\title{
DESIGN AND STRUCTURAL ANALYSIS OF A RACK SYSTEM FOR USING IN AGRICULTURE
}

\author{
Miroslav Blatnickýㄹ, Ján Dižo ${ }^{1}$, Dalibor Barta ${ }^{1}$ \\ ${ }^{1}$ Department of Transport and Handling Machines, Faculty of Mechanical Engineering, University of Žilina, \\ Univerzitná 8215/1, 01026 Žilina, Slovakia
}

\begin{abstract}
BLATNICKÝ MIROSLAV, DIŽO JÁN, BARTA DALIBOR. 2018. Design and Structural Analysis of a Rack System for Using in Agriculture. Acta Universitatis Agriculturae et Silviculturae Mendelianae Brunensis, 66(3): 641-646.

The paper deals with a construction design and structural analysis of the rack system which will be used for storage of steel tubes of pressure pipeline for fodder mixtures transportation in agricultural company. Structure of the designed equipment is made by the welding of steel parts and consists of the main framework and four pull-out racks on both sides. Racks move by means of human power through a rotating crank. Every individual pull-out racks is able to carries pipes of various dimensions, both length and diameter with total weight up to 3 tons with respect to customer requests. Since it is a prototype's structure, we have designed main dimensions of it, material and technology for production and performed also structural analyses as the integral part of every engineering design. Structural analyses were conducted by means of numeric procedure known as finite element method. With respect to the used steel profiles shell elements were used for FE model. Analyses were performed for maximal loading cases in order to identify the level of safety in the most exposed locations of the structure.
\end{abstract}

Keywords: transport and handling machines, rack system, Adina, numerical calculation

\section{INTRODUCTION}

Generally, handling equipment consists of bearing construction, driving mechanism and other parts (various additional equipment, e.g. a cab). The steel structure forms a basic bearing part of any handling equipment. Mostly it means the bearing structure of all equipment working parts which transmits all external loads affecting the equipment. The shape of the steel structure defines its kind and purpose of use (Drozdziel, 2017). Its production is carried out by joining parts into larger constructions by means of either riveting (an older way), or welding (nowadays the most common way).

In this contribution we introduce the prototype design of a rack system, which will be situate in an agricultural company. It is intended for a storage of steel pipes of high pressure pipelines used for loose fodder mixture transportation (Manolkar, 2017; Bartoň, 2017). For this reason, the designed steel construction of rack system (Fig. 1) will be constructed by welding. Among the most important customer's requirements we can include the safety of the construction. The steel construction should be light and rigid enough to ensure the economy of production and operation, it should also be aesthetic and take into account the perfect arrangement of the steel construction as a whole, it should allow a safe access to all mechanisms, and it should also have an appropriate division with regard to its assembly.

In designing the steel construction we consider particularly safety and consequently, reliability (summary of characteristics and factors which affect usability, no-failure operation, and maintenance of the steel construction) (Galliková, 2016). The construction will be formed by means of welding and we have to ensure the welding capability of material. Welding steel without special requirements and welding conditions (due 


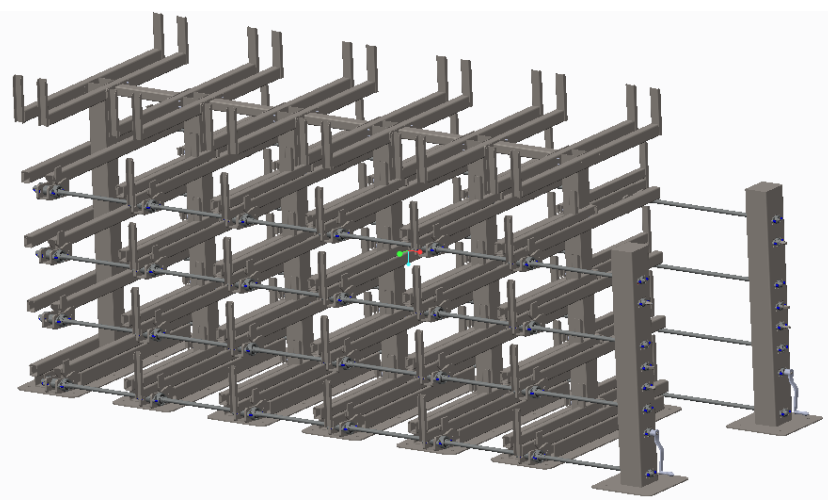

1: Model of the designed structure prototype

to the demand for the economy of production) cannot contain more than $0.18 \%$ of carbon resulting in strength less than $400 \mathrm{MPa}$ of the given classes of steel used for the steel construction. To increase strength we can use steel with other alloyed element, for example 11523 steel has strength $520 \mathrm{MPa}$ and is alloyed by manganese (max: $1.5 \% \mathrm{Mn}, 0.55 \% \mathrm{Si}, 0.3 \% \mathrm{Cr}, 0.3 \% \mathrm{Ni}$ ). That's why we have chosen STN 11523 steel as basic material of rack system construction (Bajla, 2014). In welded constructions influenced statically and dynamically we use butt and fillet welds. The calculation is run on dimension principles with certain specification. To save storage area, for the company it is important that the rack, serving for material storage, provides the storage in several layers in height. To alleviate handling with material stored in the rack and to increase clarity, one kind of material is deposited together if possible. Moreover, we have to take into account the principle that if we put more kinds of material into the rack, loading and unloading of material at the bottom is time-consuming. Therefore, to increase the handling efficiency it is advisable to construct storage racks as a mechanism with a single degree of freedom, which allows to pull out the material horizontally and to grip it by means of a grab bucket.

\section{PREPARING THE FEM MODEL}

The strength analysis of the rack system will be carried out in the program ADINA by using the finite element method (FEM) (Leitner, 2015; Smetanka, 2017). As the construction consists of thin-walled tubing, it is suitable for the model to be constructed from shell elements. While modelling the shells it is necessary to prepare

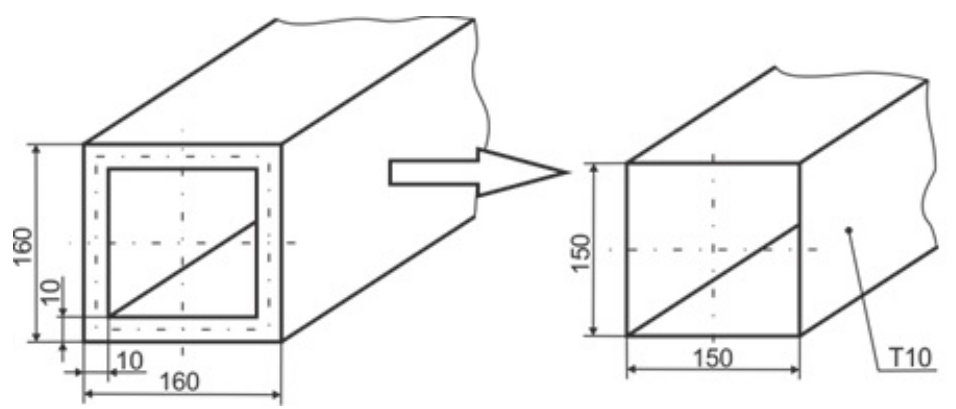

2: Preparing the shell model
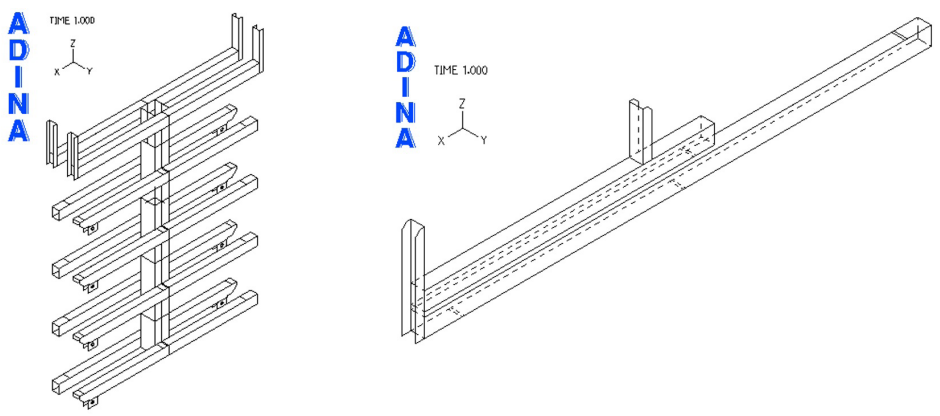

3: The geometry of the rack bearing part (on the left) and the rack arm (on the right) 
the geometric model with modified dimensions in advance. We will use so-called mid-surface and add the thickness of material (Fig. 2).

In ADINA Structures Pre-Processing we created the geometry of the shell model of the rack bearing part and the geometry of the arm shell model (Fig. 3).

Similarly, like dealing with the forces on the crank, we will solve it and divide it into two parts. The mechanism can be placed in two extreme positions when the rack is pulled-in (Fig. 4) or pulled-out (Fig. 5).

That is why we will analyse the construction twice. When simulating the pull-in position we will apply calculated reactions $R_{A}$ and $R_{B}$. On the other hand with the pull-out position we will use the reactions $R_{A}^{\prime}$ and $R_{C}$. As the construction is made from steel, we choose elastic isotropic material model with corresponding mechanical properties: Young's module of tensile elasticity $E=210 \mathrm{GPa}$, Poisson number $\mu=0.33(-)$, density of material $\rho=7,850 \mathrm{~kg} \cdot \mathrm{m}^{-3}$ The friction wheel is a structural node connected to two lifting eyes on the construction, so the reaction $R_{A}$ from the friction wheel will operate in the form of half-powers in the centre of the eyes. The reaction $R_{B}$ from the upper bearing will operate in the form of connected line load at the point of contact of the bearing and the square tubing. In the pull-out position we count the reactions $R_{A}^{\prime}$ and $R_{C}$ using a similar way.

The attachment of the model was performed by removing all degrees of freedom except moving in the directions $x$ and $y$ at the lower rims of the central beam by applying one edge point of the lower rim and removing one level of freedom in the $x$ direction at the opposing point. And we continued in forming the group of finite elements.
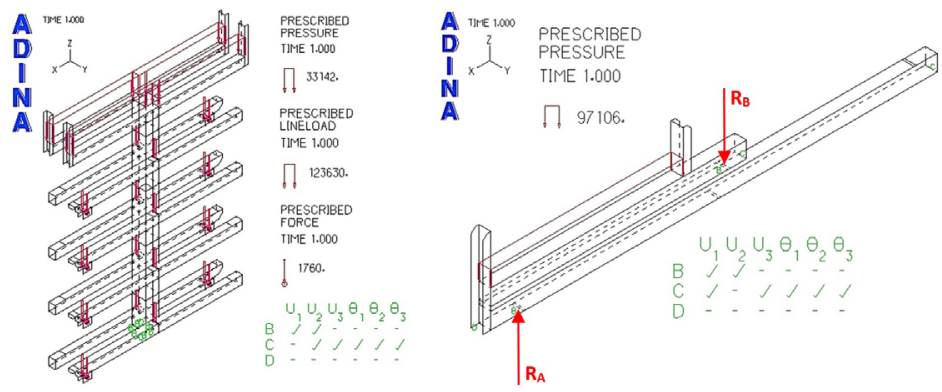

4: Limits of loaded pulled-in rack system

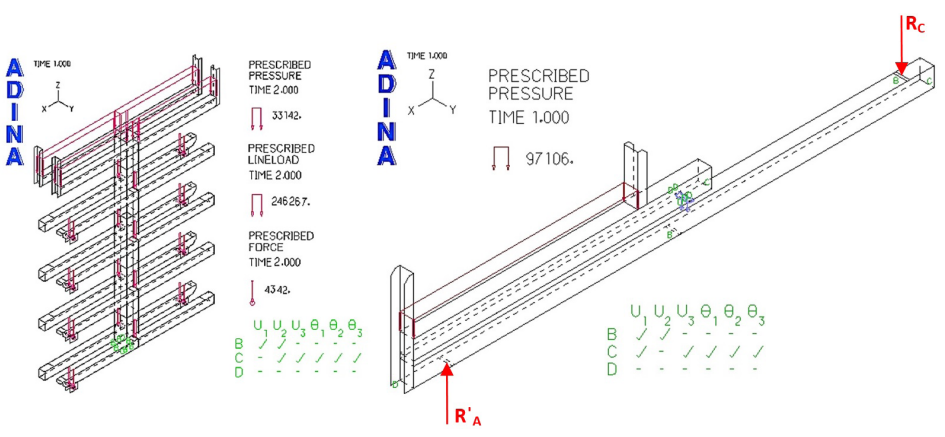

5: Limits of loaded pulled-out rack system
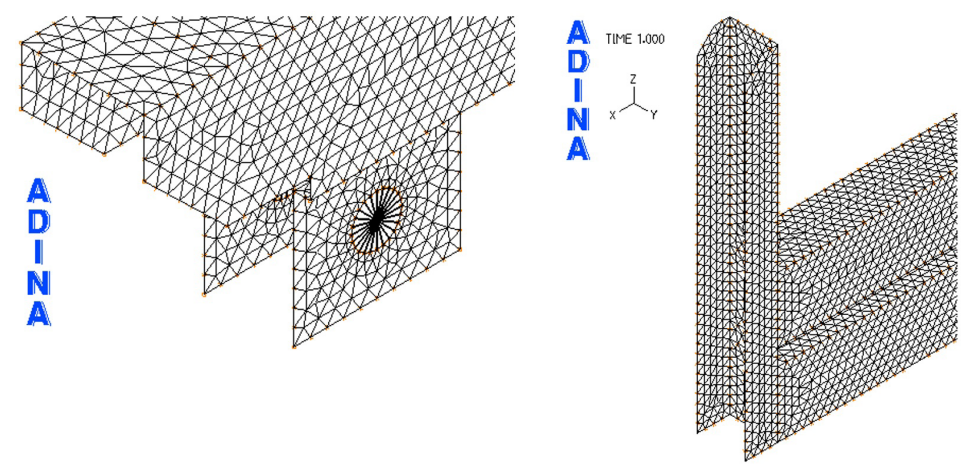

6: Details of the mesh 
A single group of shell elements with certain thickness was created for each part of the model with different thickness of a wall. Then it was necessary to create a group of rod elements (Fig. 6 on the left) which filled in the lifting eyes in order to apply the forces $F_{1}$ or $F_{2}$ in the middle of the lifting eye. Taking into account the compromise between accuracy of the calculation and needed calculation we set the thickness of mesh to $10 \mathrm{~mm}$. Finally the model was meshed by linear tetrahedrons. This was also the last step in preparing the model for numerical analysis.

\section{NUMERIC STRENGTH ANALYSIS OF THE RACK SYSTEM}

Firstly, we have determined maximum permissible values of stresses in the most exposed location. As it is welded structure and considering the facts resulting from the nature of the use, we have taken into account the safety factor $k=1.7$ and the welding factor $c=0.7$, which include both common and exceptional dynamic effects. Then, the maximum permissible values of stress for both S235 (denoted) and S355 (denoted) steels are calculated as follows:

$R_{\text {per } 235}=R_{e 235} \cdot \frac{c}{k}=240 \cdot \frac{0.7}{1.7}=98 \mathrm{MPa}$

and

$R_{\text {per } 355}=R_{e 355} \cdot \frac{c}{k}=360 \cdot \frac{0.7}{1.7}=148 \mathrm{MPa}$

where $R_{e 235}$ and $R_{e 355}$ are yield stresses of the steels S235 and S355, respectively. Analytically determined values of the permissible stresses have serveed as the comparative criterion for numerical simulations.

After finishing the analysis it is necessary to switch the programme to the module Pre-Processing (Gerlici, 2009, Gerlici, 2014) in which all results of analyses are presented and evaluated. In time $t=1$ s, i.e. in the rack pull-in position, the bearing construction and the rack are in the stressed position according to Fig. 7. As seen in Fig. 7 on the left, in the pulled-in position of the racks the maximum smoothed stress in the bearing construction is $86.67 \mathrm{MPa}$, except for the point of the attachment.

The simulating value is smaller than the allowed stress in the welded construction that is $98 \mathrm{MPa}$. So for the pulled-in position the rack system is set properly. As seen in Fig. 7 on the right, the maximum smoothed stress of the rack arm is $57.09 \mathrm{MPa}$.

We will not take into account this value because the stress is at the point of applying the edge condition. The stress according to the colour scale in the picture is important. It is $52 \mathrm{MPa}$, which in comparison with permitted stress (211 MPa) for the non-welded material (the maximum of the stress is not in the point of the weld) will prove the correctness of the construction design.

In time $t=2 \mathrm{~s}$, i.e. in pulled-out position of racks, the bearing construction is in the stress according to Fig. 8 on the left. As it can be seen in Fig. 8 on the left, the maximum of the smoothed stress is $213.6 \mathrm{MPa}$ in the point of the attachment. The stress in the weld is $195 \mathrm{MPa}$. We cannot use the strength condition because the calculated stress (195 MPa) is bigger than the permitted stress in weld ( $98 \mathrm{MPa})$. On the other hand we can use the strength condition for the rack arm in the pulled-out and pulled-in position. The maximum of the simulating stress (approx. $50 \mathrm{MPa}$ ) is suitable.
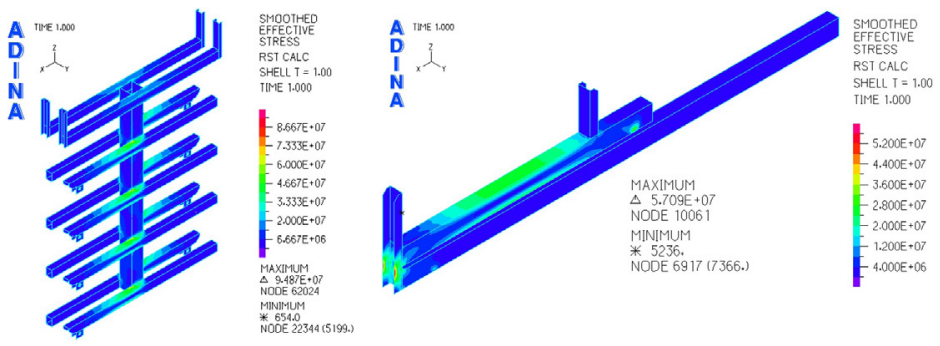

7: Fig. 7 Smoothed stress in the rack part (on the left) and rack arms (on the right) in the pulled-in position
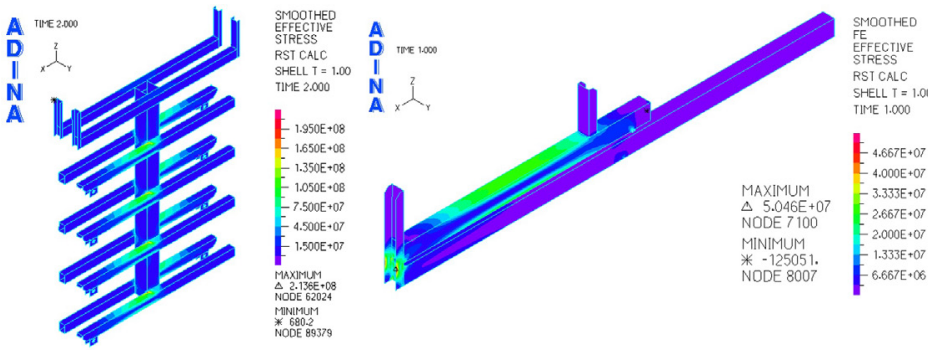

8: Fig. 8 Smoothed stress in the rack part (on the left) and rack arms (on the right) in the pulled-out position 


\section{Modification of the structure}

Based on previous results, the designed structure shows insufficiencies from the strength point of view. Therefore it is necessary to perform some modification of the overstrained locations. They are in the weld of the central beam and horizontal crossbeams of the main framework when a rack is fully loaded and pulled out.

Due to high stresses acting in the main framework of the mechanical rack system a design modification were performed. As the effective way to reduce the strain in structure we have propose to add stiffeners between the central beam and horizontal crossbeams (Fig. 9) in those locations, in which the structure does not met the stress criteria. Stiffeners are made of sheet with the thickness of $10 \mathrm{~mm}$ and $\mathrm{S} 355$ steel.
Fig. 10 shows creation of the FE model of the main framework with a stiffener. As in previous models, there were created midsurfaces and shell elements.

Such a model is prepared for re-analysis. Results of re-analyses are shown in Fig. 11.

As we can see in Fig. 11, the design modification of the main framework in welded joints of the central beam with horizontal crossbeam's connections leads to the significant stresses decreasing. The maximum smoothed stress value is $118.6 \mathrm{MPa}$ and this means, that the structure is suitable for use of the intended purpose.

In the future research we will prepare MBS model (Hauser, 2017a; Hauser, 2017b; Kostrzewski, 2017) of the designed structure for the identifying dynamical properties of individual parts of the structure and as the last step will be the implementation of the flexible body into the MBS software.

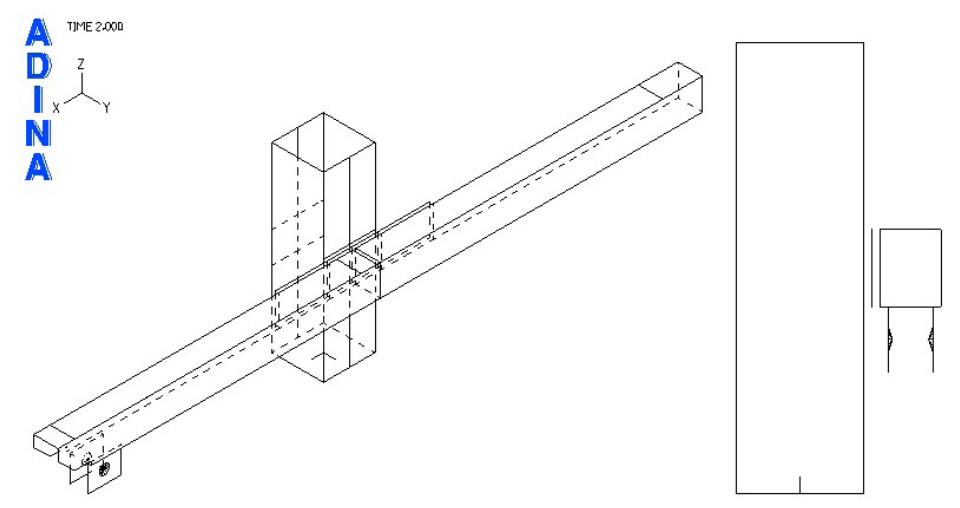

9: Fig. 9 Geometry of the main framework with added stiffeners

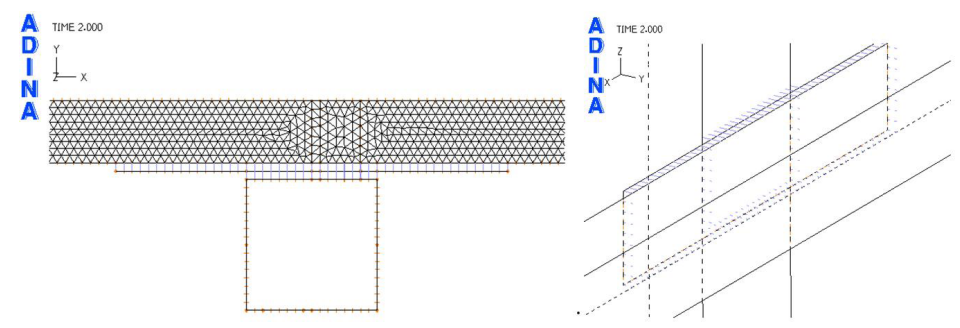

10: Fig. 10 FE model of the main framework with a stiffener and the detail of the model

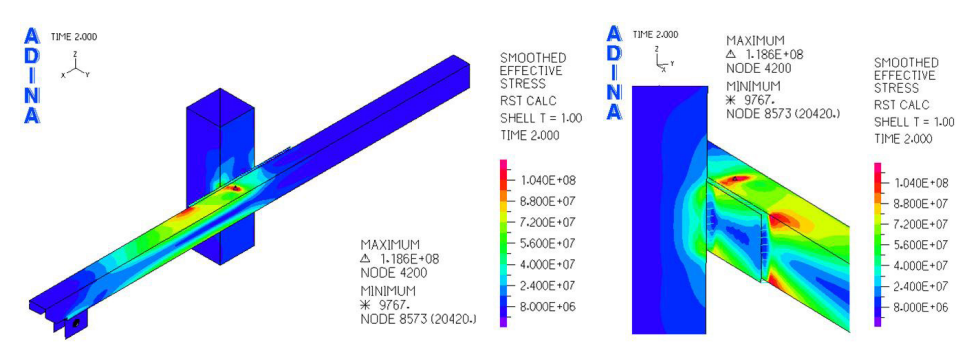

11: Fig. 11 Smoothed stress in the main framework after design modification (on the left), detail of stresses distribution in a weld joint (on the right) 


\section{CONCLUSION}

The aim of this article is the design and strength analysis of the rack with pull-out arms intended for using in an agricultural company for steel tubes storage. We described the theoretical aspects of steel constructions, which helped to achieve the objectives. The pull-out rack analysis has proved that this part of the construction meet the safety requirements while loading the pull-out or pull-in rack positions. The analysis of the bearing construction showed significant deficiencies in strength and stability of the pulled-out rack position when the welds had the stress $213.6 \mathrm{MPa}$. Therefore, design modification had to be done. The modification was based on the addition of stiffeners in joint locations of the central beam with horizontal crossbeams. After performing re-analyses we have found out, that the whole structure of the designed mechanical rack system meets estimated criteria and it is suitable for intended purpose.

Acknowledgement

The work was supported by the Cultural and Educational Grant Agency of the Ministry of Education of the Slovak Republic in project No. KEGA 077ŽU-4/2017: Modernization of the Vehicles and engines study program.

\section{REFERENCES}

BAJLA, J., BRONČEK, J., ANTALA, J. and SEKEREŠOVÁ, D. 2014. Mechanical Engineering Tables. Selection Standards. Slovak Office of Standards, Metrology and Testing, 2014.

BARTON, S., CERVINKA, J. and POSPISIL, J. 2017. Stability modelling of boom mover by the maple program. Acta Universitatis Agriculturae et Silviculturae Mendelianae Brunensis, 65(4): 1113-1119.

DROZDZIEL, P., WAWER, K., MADLENAK, R. and MUSSABEKOV, M.O. 2017. Concepts of load handling devices, adjusted do light goods vehicles of the weight up to 3.5t. Communications - Scientific Letters of the University of Žilina, 19(2): 96-102.

GALLIKOVÁ, J., POPROCKY, R. and VOLNA, P. 2016. Implementation of FMEA method in maintenance of semi-trailer combination. Diagnostyka, 17(4): 85-92.

GERLICI, J. and LACK, T. 2009. Iterative method railway wheel profile design. Komunikacie, 11(2): 49-56.

GERLICI, J., LACK, T. and HARUSINEC, J. 2014. Realistic simulation of railway operation on the RAILBCOT test stand. Applied Mechanics and Materials, 486: 387-395.

HAUSER, V., NOZHENKO, O., KRAVCHENKO, K., LOULOVA, M., GERLICI, J. and LACK, T. 2017a. Proposal of a mechanism for setting bogie wheelset to radial position while riding along track curve. Manufacturing Technology, 17(2): 186-162.

HAUSER, V., NOZHENKO, O., KRAVCHENKO, K., LOULOVA, M., GERLICI, J. and LACK, T. 2017b. Proposal of a steering mechanism for tram bogie with three axle boxes. Procedia Engineering, 192: 289-294.

KOSTRZEWSKI, M. and MELNIK, R. 2017. Numerical dynamics study of a rail vehicle with differential gears. Procedia Engineering, 192: 439-444.

LEITNER, B. and VASKO, M. 2015. Design and modelling of tank wagon assembly operations in CAM environment. In: Proceedings of the $19^{\text {th }}$ International Conference on Transport Means, TRANSPORT MEANS 2015. October 22-23. Lithuania: Kaunas University of Technology, Kaunas, Lithuania.

MANOLKAR, R. J. 2017. Hydraulic fodder baler machine. In: Proceedings of the $27^{\text {th }}$ Annual Conference on Industrial Engineering and Operations Management, IEOM 2017. Hotel Sofitel Rabat Jardin des RosesRabat, 11-13 April, Morocco. KLS Gogte Institute of Technology, Karnataka, India.

SMETANKA, L. and STASTNIAK, P. 2017. Analysis of contact stresses of theoretical and worn profile by using computer simulation. Manufacturing Technology, 17(4): 580-585.

Miroslav Blatnický: miroslav.blatnicky@fstroj.uniza.sk

Ján Dižo: jan.dizo@fstroj.uniza.sk

Dalibor Barta: dalibor.barta@fstroj.uniza.sk 